\title{
Aromatase Deficiency due to a Novel Mutation in CYP19A1 Gene
}

\author{
(1) Edip Unal ${ }^{1}$, (1) Ruken Yıldırım², (1) Funda Feryal Taş $^{1}$, (1) Vasfiye Demir ${ }^{3}$, (1) Hüseyin Onay ${ }^{4}$, (1) Yusuf Kenan Haspolat ${ }^{1}$ \\ 1 Dicle University Faculty of Medicine, Department of Pediatric Endocrinology, Diyarbakır, Turkey \\ 2Diyarbakır Children's Hospital, Clinic of Pediatric Endocrinology, Diyarbakır, Turkey \\ ${ }^{3}$ Kocaköy Family Health Center, Diyarbakır, Turkey \\ ${ }^{4}$ Ege University Faculty of Medicine, Department of Medical Genetics, Izmir, Turkey
}

\section{What is already known on this topic?}

Aromatase deficiency is an autosomal recessive genetic disorder that is rarely reported in the literature. Aromatase enzyme converts androgens into estrogen in many tissues. Aromatase deficiency causes ambiguous genitalia in the female fetus and maternal virilization during the pregnancy due to increased concentration of androgens. Ovaries are usually large and polycystic in girls with aromatase deficiency.

\section{What this study adds?}

We identified a novel mutation in the CYP19A1 gene in a patient who presented with ambiguous genitalia and maternal virilization during pregnancy. In our patient, the ovaries were hypoplasic despite increased gonadotropin levels

\begin{abstract}
Aromatase deficiency is a rare autosomal recessive genetic disorder with an unknown incidence. Aromatase converts androgens into estrogen in the gonadal and extra-gonadal tissues. Aromatase deficiency causes ambiguous genitalia in the female fetus and maternal virilization (hirsutism, acne, cliteromegaly, deep voice) during pregnancy due to increased concentration of androgens. A 19 months old girl patient was assessed due to presence of ambiguous genitalia. There were findings of maternal virilization during pregnancy. The karyotype was 46,XX. Congenital adrenal hyperplasia was not considered since adrenocorticotropic hormone, cortisol, and 17-hydroxyprogesterone levels were within normal ranges. At age two months, follicle-stimulating hormone and total testosterone levels were elevated and estradiol level was low. Based on these findings, aromatase deficiency was suspected. A novel homozygous mutation IVS7-2A > G (c.744-2A > G) was identified in the CYP19A1 gene. Pelvic ultrasound showed hypoplasic ovaries rather than large and cystic ovaries. We identified a novel mutation in the CYP19A1 gene in a patient who presented with ambiguous genitalia and maternal virilization during pregnancy. Presence of large and cystic ovaries is not essential in aromatase deficiency.
\end{abstract}

Keywords: Aromatase deficiency, CYP19A1 gene, maternal virilization, ambiguous genitalia

\section{Introduction}

Aromatase is a member of the cytochrome P450 superfamily and encoded by the CYP19A1 gene located on chromosome $15 q 21.1$ (1). It is the key enzyme for estrogen biosynthesis in all vertebrates. CYP19A1 gene and aromatase are expressed in numerous tissues including ovaries, testes, placenta, adipose tissue, skin and brain. Aromatase catalyzes the three precursors including androstenedione, testosterone and 16- $\alpha$-hydroxy dehydroepiandrosterone sulfate (after conversion to
16- $\alpha$-hydroxyandrostenedione) into estrone, estradiol and estriol, respectively $(1,2,3)$. Aromatase deficiency leads to increased androgen levels both in the mother and the fetus. Aromatase deficiency causes specific signs of maternal virilization including cystic acne, hirsutism, cliteromegaly and deep voice while resulting in significant masculinization in the external genitalia of the female fetus (4).

In this study, we present a case with a novel homozygous IVS7-2A > G (c.744-2A > G) mutation in the CYP19A1 gene 
causing significant virilization both in the mother and the female fetus.

\section{Case Report}

The patient was born at term at another centre via spontaneous vaginal delivery with a birth weight of 3500 g. The parents were first-degree cousins. Ambiguous genitalia were recognized at birth. Signs of maternal virilization (hirsutism, acne, cliteromgaly, deep voice) were noted at approximately 20 weeks of gestation. The patient represented at age fifteen days. Congenital adrenal hyperplasia was not considered since adrenocorticotropic hormone, cortisol, and 17-hydroxyprogesterone levels were within normal ranges. The other parameters were as follows: follicle-stimulating hormone (FSH) $66 \mathrm{mIU} / \mathrm{mL}$ (0.24-14.2), luteinising hormone (LH) $9.7 \mathrm{mIU} / \mathrm{mL}$ (0.02-7.0), total testosterone $0.9 \mathrm{ng} / \mathrm{mL}(0.2-0.64)$, estradiol $5 \mathrm{pg} / \mathrm{mL}(<15)$. The karyotype was 46,XX and pelvic ultrasonography revealed the uterus dimensions as $5 \times 8 \times 13 \mathrm{~mm}$ (normal range $33.1 \pm 4.1 \mathrm{~mm}$ for uterus long axis), those of the right ovary as $5 \times 3 \times 3 \mathrm{~mm}(0.02 \mathrm{~mL}$; normal range 0.2-0.9 mL), and those of the left ovary as $5 \times 3 \times 3 \mathrm{~mm}(0.02 \mathrm{~mL}$; normal range 0.2-0.9 $\mathrm{mL}$ ).

At presentation to our centre at 19 months of age she had ambiguous genitalia. The patient had a body weight of $11 \mathrm{~kg}$ [standard deviation (SD) score +0.07 ] and a length of 82 $\mathrm{cm}$ (SD score + 0.48). Genital examination showed bilateral impalpable gonads, a penis-like phallus of $1.5 \mathrm{~cm}$, single penoscrotal urethral opening, and labioscrotal fusion defect (Prader stage 4). Hormonal analyses were unremarkable except for a significantly elevated FSH level (Table 1). Aromatase deficiency was considered due to the presence of maternal virilization, detection of hypergonadotropic hypogonadism during mini-puberty and low estradiol levels despite elevated total testosterone levels. CYP19A1 gene mutation analysis was performed by sequencing the coding exons and the exon-intron boundaries of the genes. Genomic DNA was isolated from peripheral blood cells with QIAGEN DNA Blood Midi Kit according to the manufacturer's protocol. To amplify the exons of the CYP19A1 gene, primers were used as listed in Table 2. Sequencing was performed with MiSeq V2 chemistry on a MiSeq instrument (Illumina California, USA) and the analysis was performed with IGV software. A novel homozygous [IVS7-2A $>$ G (c.744-2A>G)] mutation was found in the

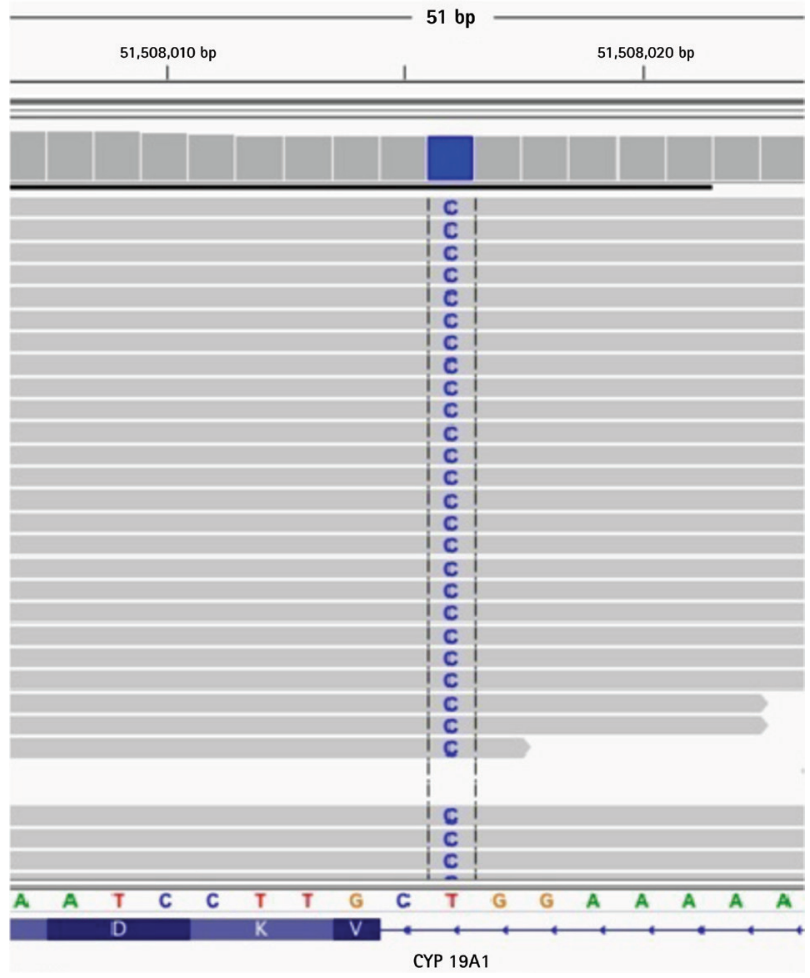

Figure 1. Homozygous mutation IVS7-2A > G (c.744-2A > G) in intron 7 of the CYP19A1 gene

\begin{tabular}{|c|c|c|c|}
\hline & 15 days & 70 days & 19 months \\
\hline FSH (mIU/mL) & $66(0.24-14.2)$ & $52.4(0.24-14.2)$ & $110(1.0-4.2)$ \\
\hline Testosterone (ng/mL) & $0.9(0.2-0.64)$ & $0.39(<0.1)$ & $0.03(<0.03-0.01)$ \\
\hline Estradiol (pg/mL) & $<5(<15)$ & $<5(5-50)$ & $<5(5-20)$ \\
\hline Cortisol (mcg/dL) & & $22.3(2.8-23.0)$ & $18.0(3.0-21.0)$ \\
\hline ACTH (pg/mL) & & $28.7(10.0-60.0)$ & $42.0(10.0-60.0)$ \\
\hline DHEA-S (ug/dL) & & $61(5-111)$ & \\
\hline Progesterone (ng/mL) & & $0.27(0.07-0.52)$ & $0.2(0.07-0.52)$ \\
\hline
\end{tabular}

FSH: follicle-stimulating hormone, LH: luteinizing hormone, 17-OH: 17-hydroxy, ACTH: adrenocorticotropic hormone, DHEA-S: sulfated dehydroepiandrosterone 
CYP19A1 gene (Figure 1). To our knowledge, this mutation has not been previously reported. The mutation was interpreted as a "disease-causing" mutation by the MutationTaster and Splice Site Finder modeling programs. The parents were heterozygous carriers for the same mutation (Figure 2).

Informed consent was obtained from the parents for publication of the case.

\section{Discussion}

Aromatase deficiency is a rare disease caused by CYP19A1 gene mutation and characterized by a decrease in estrogen

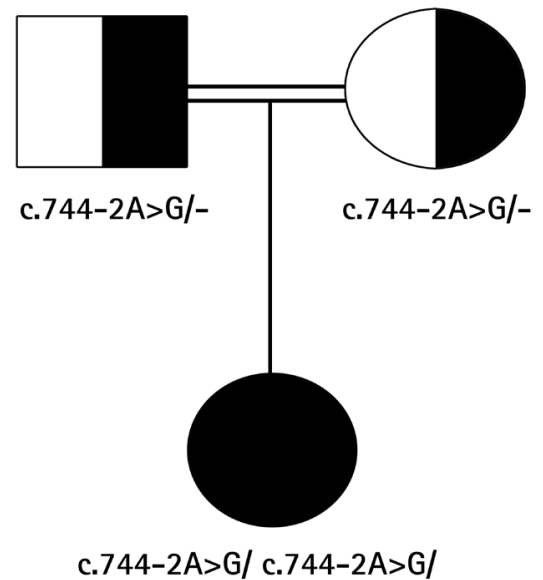

Figure 2. Pedigree of the patient's family. Solid black symbols depict affected individuals; half-filled symbols represent heterozygous carriers

\begin{tabular}{ll}
\hline $\begin{array}{l}\text { Table } 2 \text {. Primers used for sequencing the coding region } \\
\text { of the } \text { CYP19A1 gene }\end{array}$ \\
\hline CYP19A1-2F & TCTGAAGCAACAGGAGCTAT \\
CYP19A1-2R & CAGAGATCTTTCCAGGTTTG \\
CYP19A1-3F & GAAGTGAAGAGCCTCATGTT \\
CYP19A1-3R & TGTTAGATTTCTGGGGATTG \\
CYP19A1-4F & CAACATGCATTTGCTAAGAG \\
CYP19A1-4R & CTGGGTGATAGAGTCAGAGC \\
CYP19A1-5F & TTAGGAGACCACAGAAAAGC \\
CYP19A1-5R & GCAGAAACACTAGGGAAAAA \\
CYP19A1-6F & GAAGATGGAATCTTGCTGAG \\
CYP19A1-6R & TTAATCAACAGCTCCCTTGT \\
CYP19A1-7F & CACTTACTCATAAGCACCAAT \\
CYP19A1-7R & TTGGATTGGGATTACAGAAC \\
CYP19A1-8F & TCAATCACAGAGACATGTGG \\
CYP19A1-8R & TCTTTTCCGTCTATCTGGTG \\
CYP19A1-9F & GCTGGTGTGCATTAGAATTA \\
CYP19A1-9R & GCACAGGGAATGAGTAAGAA \\
CYP19A1-10F & AGGGCATTGTAGCTGATAAC \\
CYP19A1-10R & TGTTCACTGTGAGGATGACA \\
\hline
\end{tabular}

synthesis. Aromatase deficiency is an autosomal recessive disorder and was first described by Shozu et al (5). To date, a total of 36 cases from various ethnic origins have been reported in the literature $(1,2,6,7,8,9,10,11,12,13,14)$. In patients with aromatase deficiency, more than 30 distinct mutations have been identified in the CYP19A1 gene, including missense, nonsense, small deletions and insertions, splice-site mutations, and one large intragenic deletion $(1,2,6,7,8,9,10,11,12,13,14,15,16)$. Most of these mutations have been found to be located in exon 9 and 10 (9). The mutations identified in cases from Turkey have been reported in different exons (exon 5, 10, 11) $(16,17,18)$. In our patient, the mutation was located in intron 7 of the CYP19A1 gene.

Clinical characteristics of patients with aromatase deficiency vary depending on gender, age and enzymatic activity (1). Aromatase deficiency leads to an increase in intrauterine androgen concentration, thereby result in varying degrees of postnatal virilization in the external genitalia in girls and no change in the external genitalia in boys at birth. Our patient had a karyotype of 46,XX and was born with ambiguous genitalia (Prader stage 4). During infancy and childhood there are usually no symptoms of aromatase deficiency (particularly in boys) while some girl patients may present with abdominal symptoms of ovarian cysts because of mild changes in the hypothalamic-pituitary-gonadal axis due to lack of feedback regulation (3). Aromatase deficiency may lead to a number of clinical conditions in adolescent girls such as delayed puberty, hypergonadotropic hypogonadism, multicystic ovaries and primary amenorrhea in accordance with estrogen deficiency. Signs of virilization such as acne, hirsutism, and cliteromegaly in keeping with androgen excess may also be present $(1,2,19,20)$. Estrogen deficiency, on the other hand, causes delayed epiphyseal closure, eunuchoid body habitus, osteopenia and osteoporosis that develop in both genders (21). A previous study reported a 27-year-old patient with bone pain and recurrent bone fractures secondary to minor trauma. The patient had open epiphyses and also developed lumbar osteoporosis. Aromatase deficiency was detected and the study concluded that estrogen has a key role in maintaining bone mineral density (17).

In most of the fetuses with aromatase deficiency, early (12 weeks) or late onset (up to 30 weeks) maternal virilization can be noted $(20,22)$. The non-aromatized fetoplacental and maternal androgen precursors are converted to testosterone in the placenta and also in peripheral maternal tissues, thereby resulting in maternal virilization. After giving birth, the signs of virilization disappear gradually and the androgen levels return to normal (1). In our 
patient, the signs of maternal virilization (hirsutism, acne and deep voice) developed at approximately 20 weeks of gestation. Although hirsutism and acne resolved after birth, interestingly the deep voice persisted, which was consistent with the literature (13).

Both basal and GnRH-stimulated FSH levels have been shown to be higher in girls with aromatase deficiency during the first two years of life compared to normal subjects (50-75 and 200-255 mIU/mL, respectively). However, the estradiol and estrone levels tend to be remarkably low during this same period $(22,23)$. Moreover, basal LH is often within normal limits or slightly elevated during infancy (5-10 mIU/ $\mathrm{mL}$ ). A previous study showed that in a girl with aromatase deficiency, the FSH and LH levels persistently increased and multicystic ovaries developed between the ages of three and four years (22). However, Belgorosky et al $(23,24)$ reported that the basal FSH and LH levels in a girl with aromatase deficiency were found to be increased during mini-puberty and to show a dramatic decrease between two and five months. In our patient, gonadotropin (FSH, LH) levels were found to be elevated since birth.

In girls with aromatase deficiency, the ovaries are usually large and polycystic in every stage of life (newborn, childhood and puberty) due to the chronic stimulation by gonadotropins that cannot be suppressed owing to estrogen deficiency or androgen excess $(1,2)$. In our patient, no cystic formation was observed in the ovaries despite high gonadotropin levels and also the ovarian volumes were below the age-matched limits. To date, hypoplasic ovaries have been reported in a total of five cases from three studies, the characteristics of which were similar to those of our patient $(9,16,18)$.

Literature reviews indicate that there is little documentation on the effects of estrogen replacement to prevent estrogen deficiency in women with aromatase deficiency. Moreover, there is no consensus on the dosage and age of initiation of estrogen replacement therapy. On the other hand, data regarding early initiation of the treatment and the long-term follow-up of the patients are extremely rare. To our knowledge, there has been only one study investigating the effects of estrogen replacement therapy on longitudinal growth, bone age maturation, multicystic ovaries, bone density and regulation of the pituitary gonadotropin feedback in a girl with aromatase deficiency who was started on low-dose estrogen therapy at the age of 3.5 years and continued the therapy until the age of 15 years. The study revealed that estrogen is required for normal growth, pituitary-gonadal development and bone maturation not only in puberty but also in early childhood (3). In a review of treatment of aromatase deficiency, it was reported that estrogen replacement therapy can be initiated at as early as two years of age. The study also noted that this treatment should be initiated and sustained with the lowest dose of estrogen possible to prevent the development of ovarian cysts and to avoid early development of breasts and acceleration of bone age. The study suggested that oral conjugated estrogens $(0.15 \mathrm{mg} /$ day or every other day) or micronized estradiol $(0.25 \mathrm{mg} /$ day or every other day) can be used and the dose may be titrated to maintain the suppression of FSH and LH (4). In view of these findings, low-dose estrogen replacement therapy was planned for our patient at age two years for enhancement of the development of uterus and ovaries, normal growth, bone maturation and normalization of bone mineral density.

In conclusion, the case reported here presented with ambiguous genitalia and exisiting aromatase deficiency, findings which were due to a novel mutation in the CYP19A1 gene. Presence of large and cystic ovaries is not essential in aromatase deficiency. On the contrary, the ovaries may be hypoplastic as in this case and a number of other previous reports $(9,16,18)$. Aromatase deficiency should be kept in mind in patients with 46,XX karyotype presenting with ambiguous genitalia along with the signs of maternal virilization.

\section{Ethics}

Informed Consent: Written informed consent was obtained from the parents.

Peer-review: Externally and internally peer-reviewed.

\section{Authorship Contributions}

Concept: Edip Unal, Ruken Yıldırım, Funda Feryal Taş, Yusuf Kenan Haspolat, Design: Edip Unal, Vasfiye Demir, Yusuf Kenan Haspolat, Data Collection or Processing: Edip Unal, Hüseyin Onay, Ruken Yıldırım, Funda Feryal Taş, Analysis or Interpretation: Edip Unal, Vasfiye Demir, Hüseyin Onay, Yusuf Kenan Haspolat, Literature Search: Edip Unal, Ruken Yıldırım, Vasfiye Demir, Funda Feryal Taş, Writing: Edip Unal, Hüseyin Onay.

Financial Disclosure: The authors declared that this study received no financial support.

\section{References}

1. Belgorosky A, Guercio G, Pepe C, Saraco N, Rivarola MA. Genetic and clinical spectrum of aromatase deficiency in infancy, childhood and adolescence. Horm Res 2009;72:321-330. Epub 2009 Oct 21.

2. Verma N, Jain V, Birla S, Jain R, Sharma A. Growth and hormonal profile from birth to adolescence of a girl with aromatase deficiency. J Pediatr Endocrinol Metab 2012;25:1185-1190. 
3. Janner $\mathrm{M}$, Flück $\mathrm{CE}$, Mullis PE. Impact of estrogen replacement throughout childhood on growth, pituitary-gonadal axis and bone in a 46,XX patient with CYP19A1 deficiency. Horm Res Paediatr 2012;78:261-268. Epub 2012 Sep 6

4. Bulun SE. Aromatase and estrogen receptor $\alpha$ deficiency. Fertil Steril 2014;101:323-329.

5. Shozu M, Akasofu K, Harada T, Kubota Y. A new cause of female pseudohermaphroditism: placental aromatase deficiency. J Clin Endocrinol Metab 1991;72:560-566.

6. Hauri-Hohl A, Meyer-Boni M, Lang-Muritano M, Hauri-Hohl M, Schoenle EJ, Biason-Lauber A. Aromatase deficiency due to a functional variant in the placenta promoter and a novel missense mutation in the CYP19A1 gene. Clin Endocrinol (Oxf) 2011;25:39-43.

7. Chen Z, Wang O, Nie M, Elison K, Zhou D, Li M, Jiang Y, Xia W, Meng $X$, Chen S, Xing $X$. Aromatase deficiency in a Chinese adult man caused by novel compound heterozygous CYP19A1 mutations: effects of estrogen replacement therapy on the bone, lipid, liver and glucose metabolism. Mol Cell Endocrinol 2015;399:32-42. Epub 2014 Oct 6

8. Ludwikowski B, Heger S, Datz N, Richter-Unruh A, González R. Aromatase deficiency: rare cause of virilization. Eur J Pediatr Surg 2013;23:418-422. Epub 2012 Oct 23

9. Gagliardi L, Scott HS, Feng J, Torpy DJ. A case of aromatase deficiency due to a novel CYP19A1 mutation. BMC Endocr Disord 2014;19:14-16.

10. Bouchoucha N, Samara-Boustani D, Pandey AV, Bony-Trifunovic H, Hofer G, Aigrain Y, Polak M, Flück CE. Characterization of a novel CYP19A1 (aromatase) R192H mutation causing virilization of a 46,XX newborn, undervirilization of the $46, \mathrm{XY}$ brother, but no virilization of the mother during pregnancies. Mol Cell Endocrinol 2014;390:8-17. Epub 2014 Apr 4

11. Marino R, Perez Garrido N, Costanzo M, Guercio G, Juanes M, Rocco C, Ramirez P, Warman DM, Ciaccio M, Pena G, Feyling JG, Miras M, Rivarola MA, Belgorosky A, Saraco N. Five new cases of 46,XX aromatase deficiency: clinical follow-up from birth to puberty, a novel mutation, and a founder effect. J Clin Endocrinol Metab 2015;100:301307. Epub 2014 Nov 21

12. Saraco N, Nesi-Franca S, Sainz R, Marino R, Marques-Pereira R, La Pastina J, Perez Garrido N, Sandrini R, Rivarola MA, de Lacerda L, Belgorosky A. An intron 9 CYP19 gene variant (IVS9 + 5G > A), present in an aromatase-deficient girl, affects normal splicing and is also present in normal human steroidogenic tissues. Horm Res Paediatr 2015;84:275-282. Epub 2015 Aug 5

13. Zhu WJ, Cheng T, Zhu H, Han B, Fan MX, Gu T, Zhao SX, Liu Y, Cheng KX, Song HD, Qiao J. Aromatase deficiency: a novel compound heterozygous mutation identified in a Chinese girl with severe phenotype and obvious maternal virilization. Mol Cell Endocrinol 2016;433:66-74. Epub 2016 May 30
14. Mazen I, McElreavey K, Elaidy A, Kamel AK, Abdel-Hamid MS. Aromatase Deficiency due to a Homozygous CYP19A1 Mutation in a 46,XX Egyptian Patient with Ambiguous Genitalia. Sex Dev 2017;11:275-279. Epub 2018 Jan 12

15. Lanfranco F, Zirilli L, Baldi M, Pignatti E, Corneli G, Ghigo E, Aimaretti G, Carani C, Rochira V. A novel mutation in the human aromatase gene: insights on the relationship among serum estradiol, longitudinal growth and bone mineral density in an adult man under estrogen replacement treatment. Bone 2008;43:628-635. Epub 2008 May 23

16. Akçurin S, Türkkahraman D, Kim WY, Durmaz E, Shin JG, Lee SJ. A Novel Null Mutation in P450 Aromatase Gene (CYP19A1) Associated with Development of Hypoplastic Ovaries in Humans. J Clin Res Pediatr Endocrinol 2016;8:205-210. Epub 2016 Apr 18

17. Carani C, Qin K, Simoni M, Faustini-Fustini M, Serpente S, Boyd J, Korach KS, Simpson ER. Effect of testosterone and estradiol in a man with aromatase deficiency. N Engl J Med 1997;337:91-95.

18. Morishima A, Grumbach MM, Simpson ER, Fisher C, Qin K. Aromatase deficiency in male and female siblings caused by a novel mutation and the physiological role of estrogens. J Clin Endocrinol Metab 1995;80:3689-3698.

19. Korach KS. Insights from the study of animals lacking functional estrogen receptor. Science 1994;266:1524-1527.

20. Baykan EK, Erdoğan M, Özen S, Darcan Ş, Saygill LF. Aromatase deficiency, a rare syndrome: case report. J Clin Res Pediatr Endocrinol 2013;5:129-132.

21. Mullis PE, Yoshimura N, Kuhlmann B, Lippuner K, Jaeger P, Harada H. Aromatase deficiency in a female who is compound heterozygote for two new point mutations in the P450arom gene: impact of estrogens on hypergonadotropic hypogonadism, multicystic ovaries, and bone densitometry in childhood. J Clin Endocrinol Metab 1997;82:17391745

22. Conte FA, Grumbach MM, Ito Y, Fisher CR, Simpson ER. A syndrome of female pseudohermaphrodism, hypergonadotropic hypogonadism, and multicystic ovaries associated with missense mutations in the gene encoding aromatase (P450arom). J Clin Endocrinol Metab 1994;78:1287-1292.

23. Belgorosky A, Pepe C, Marino R, Guercio G, Saraco N, Vaiani E, Rivarola MA. Hypothalamic-pituitary-ovarian axis during infancy, early and late prepuberty in an aromatase-deficient girl who is a compound heterocygote for two new point mutations of the CYP19 gene. J Clin Endocrinol Metab 2003;88:5127-5131.

24. Lin L, Ercan O, Raza J, Burren CP, Creighton SM, Auchus RJ, Dattani MT, Achermann JC. Variable phenotypes associated with aromatase (CYP19) insufficiency in humans. J Clin Endocrinol Metab 2007;92:982990. Epub 2006 Dec 12 